\title{
A review on the trend of livestock breeds in Laos
}

\author{
Somsy Xayalath ${ }^{1,2}$ - Malam Abulbashar Mujitaba ${ }^{1}$ - Arth David Sol Valmoria Ortega ${ }^{1}$ - József Rátky \\ ${ }^{1}$ Doctoral School of Animal Husbandry, University of Debrecen, Böszörményi Street 138, 4032 Debrecen, Hungary \\ ${ }^{2}$ Institute of Animal Science, Biotechnology and Nature Conservation, Faculty of Agricultural and Food Sciences and Environmental \\ Management, University of Debrecen, Böszörményi Street 138, 4032 Debrecen, Hungary \\ ${ }^{3}$ University of Veterinary Medicine, 1078 Budapest, István Street 2, Hungary. \\ xayalath.somsy@agr.unideb.hu
}

\section{SUMMARY}

\begin{abstract}
However, the livestock sector is considered an essential role in farmers' livelihood, even local breeds are still the critical component of animal breeding in Laos. Thus, there is a need to review the previous, current situation and future prospects for Laos' livestock production. It aimed to study the different traits among the existing dominant local and improved livestock breeds (cattle, pig, and goat) and a more in-depth study on the livestock sector's previous evolving and future prospects. Our findings revealed that the general trend of livestock population in Laos increased year-by-year for over 45 years, except for 1995 to 2000. It was decreased by almost 22\% due to the new national strategy on economic revolution. The first foreign breeds were introduced into Laos, i.e., Large White, Landrace, and Duroc in 1980, Red Sindhi bulls in 1998, the frozen semen of Red Brahman 2003, and Bach Thao goats between 2001 to 2003. Unfortunately, many data are still not precise for introducing other foreign breeds like Boer goats, Thai Grey and Red Brahman. There were many missing data on the improvement of livestock breeds in Laos, including the local and improved breeds' reproductive and productive performance, which needs more studies and researches. We concluded that the semi-complex farm operation should be applied to improve livestock breeding and their productions in Laos.
\end{abstract}

Keywords: livestock production; Local and improved breeds; livestock development; Laos

\section{INTRODUCTION}

In 2015, agriculture production contributed almost $18 \%$ in GDP, including $2.36 \%$ from livestock production (Lao Statistic Bureau, 2015). In 2010 and 2015, Laos' amount of meat production rose from 296,086 tons to 387,734 tons. This increase can provide meat for consumption around $48 \mathrm{~kg}$ person $^{-1} \mathrm{year}^{-1}$ on average in 2012 (average $42 \mathrm{~kg}$ person $^{-1}$ year $^{-1}$ in the remote areas, $56 \mathrm{~kg}$ in the urban), and $53 \mathrm{~kg}$ in 2014 (Ministry of planning and investment, 2016). Livestock production contributed to households' income for farmers in mountainous areas about 50\%, and around $30 \%$ in the lowland (Stur et al., 2002). Almost $98 \%$ of livestock farmers in Laos own at least one local breed of cattle, buffalos, pigs, and goats. Throughout 45 years, Livestock Research Center (LRC) has been thriving to improve and develop local breeds of livestock and poultry (cattle, pigs, goats, and chickens) by enhancing their productive and reproductive performance. Enormously, Lao cattle crossbred with Red-Brahman and RedSindhi bulls imported from Vietnam to increases calves' birth weight from $12 \mathrm{~kg}$ to $21 \mathrm{~kg}$ and increases cattle's market weight from $250 \mathrm{~kg}$ to $450 \mathrm{~kg}$ (Keonouchanh et al., 2014). The strategy for an agricultural development plan for 2011 to 2020 indicated that the local breeds of livestock are to be crossed with foreign purebreds to increase productivity, disease resistance and be marketoriented (MAF, 2010). Lao government continuously supports, protects, and promotes the livestock and poultry industries. Through these efforts, it is expected that buffalo production would be increased and will meet-up both domestic consumption and export to neighboring countries of about 124,000; 315,000 heads in 2020 and 137,$000 ; 392,000$ heads in 2025, respectively. Pock is currently the $3^{\text {rd }}$ most consumed meat in the country. In 2020 and 2025, Laos's government goals were pork production to meet the demand of around 97,500 tons and 116,200 tons. Thus, Laos's pig production system should shift from the traditional to a modernized production system, which could increase the number of sows by at least 45,000 heads by 2025 . The improvement program also covered the local goat breeds. It was projected that by 2025 , its population would hit around 250,000 heads to supply for domestic consumption (MAF, 2015). To improve local livestock breeds', the Lao government has strong cooperations at various levels ranging from regional, national, and international, to import high-performing foreign purebreds. In 1980, 120 exotic sows of Large White, Duroc, and Landrace pigs were imported from Thailand (Keonouchanh and Dengkhounxay, 2017). Similarly, in 1998 and 2003, 4 Red Sindhi bulls and semen of Red Brahman were imported from Vietnam, respectively, to improve Lao local cattle breeds' genetic make-up.

This review aims to compare some noticeable local and improved livestock breeds in Laos, with special regards to cattle, pigs, and goats. Together with the above mentioned, we also aimed to deeply evaluate the previous development and future trends of those livestock breeds.

\section{LIVESTOCK POPULATION AND DISTRIBUTION}

The overall livestock population in Laos has been increased year-by-year for 45 years until now. However, it experienced a decrease of nearly $22 \%$ in 2000 compared to 1995 . This is because of the new national strategy on economic revolution, especially a free zone for crop production, but rose again until 2019. 
There was only a $6.58 \%$ increase in 1985 due to the shift-point of new national economic revolutions. A more than 5 times increased (32\%) was observed five years later (Table 1). Then comes a slight decrease in 2015 because of more rubber, cassava, and other cash crop production.

Table 1. Livestock population in Laos from 1975-2019 (thousand heads)

\begin{tabular}{lcccccccccc}
\hline \multirow{2}{*}{ Livestock types } & \multicolumn{9}{c}{ Year } \\
\cline { 2 - 10 } & $\mathbf{1 9 7 6}$ & $\mathbf{1 9 8 0}$ & $\mathbf{1 9 8 5}$ & $\mathbf{1 9 9 0}$ & $\mathbf{1 9 9 5}$ & $\mathbf{2 0 0 0}$ & $\mathbf{2 0 0 5}$ & $\mathbf{2 0 1 0}$ & $\mathbf{2 0 1 5}$ & $\mathbf{2 0 1 9}$ \\
\hline Buffalo & 668 & 855 & 721 & 1,060 & 1,191 & 1,007 & 1,097 & 1,183 & 1,153 & 1,222 \\
Cattle & 326 & 445 & 628 & 851 & 1,146 & 987 & 1,272 & 1,475 & 1,766 & 2,110 \\
Pig & 764 & 1,111 & 1,191 & 1,436 & 1,580 & 1,101 & 1,827 & 2,753 & 3,122 & 4,115 \\
Goat & 31 & 48 & 81 & 109 & 153 & 100 & 190 & 366 & 481 & 648 \\
Total & 1,789 & 2,459 & 2,621 & 3,456 & 4,070 & 3,195 & 4,386 & 5,777 & 6.522 & 8,095 \\
Percent of change & - & 37.45 & 6.58 & 31.85 & 17.76 & -21.49 & 37.27 & 31.71 & 12.89 & 24.12 \\
\hline
\end{tabular}

Source: Lao Statistics Bureau (2015); MAF (2020)

\section{CATTLE BREEDS AND PRODUCTION IN LAOS}

The system of cattle production is mainly based on smallholders, especially in the rural areas. Most farmers raised their cattle as traditional free-range in fallow and forest, free-ranging in fenced-fallow, rotational grazing in fenced-pasture, and cut-and-carry (cattle are kept in pen and fed by cut grasses or other vegetation) raising system (Phouyyavong et al., 2019). Some of Laos' cattle farmers offered natural pastures, including elephant grass, Phakuay grass (Dactyloctenium aegyptium (L.) P.Beauv), Phaek grass
(Themeda triandra (Forssk.)), wild banana, sweet potato vine, dried and fresh cassava, and other forest vegetation. Overall, Laos' cattle population increased by year, for instance, 1.7 million in 2015 and 2.1 million heads in 2019 (Figure 1). However, $98 \%$ of the cattle population is raised by smallholders in the rural areas, but 170 commercial cattle farms in Laos in 2016 that covered around $56 \%$ are located in the central provinces (Napasirth \& Napasirth, 2018). In 2019, the number of commercial cattle farms dramatically increased to 326 farms, including 121 in the north, 129 in the middle, and 76 farms in the south (Table 2).

Figure 1. The trend of cattle population in Laos from 1975-2019

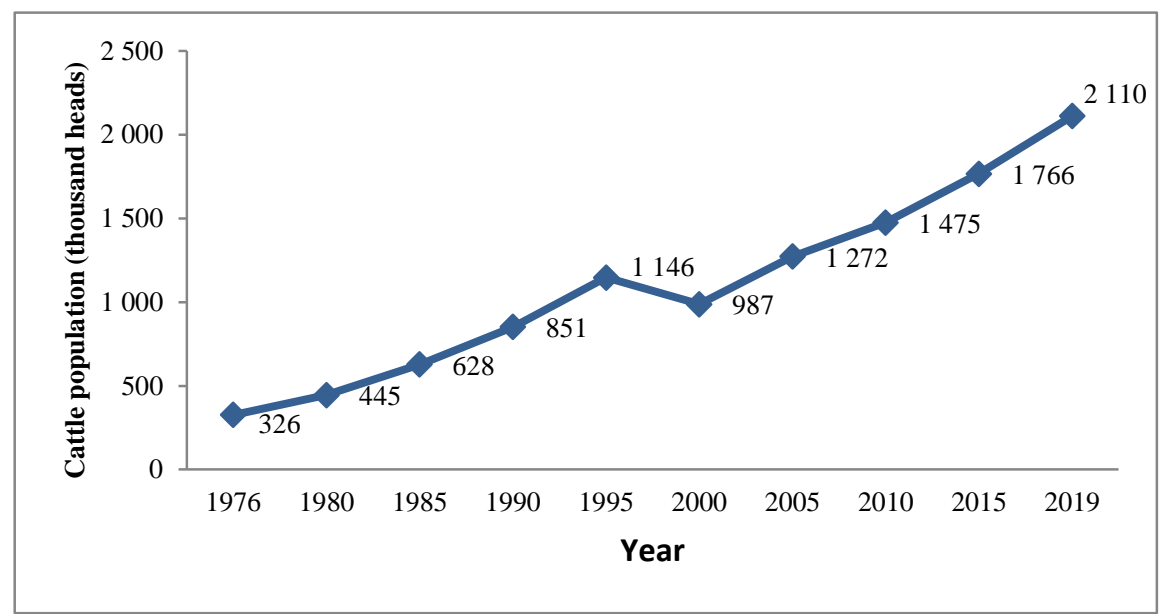

Source: Lao Statistics Bureau (2015); MAF (2020)

The number of cattle raised under commercial farms also went up to 45,537 heads compared to 2017 (26,605 heads). More than $56 \%$ of them (25,703 heads), while about $16 \%$ (7,385 heads) in the north, and $27 \%$ $(12,449$ heads) in the central parts (DLF, 2019). Studies revealed that the number of cattle raised under commercial farms is larger in the south and smaller in the north. This is in contrast to the government extension strategy on agricultural development that would like to give more effort to promote the production of large ruminant animals like buffalos and cattle in the north and promote rice and other cash production in the middle and the south (MAF, 2015).

Most cattle breeds raised in Laos are the Yellow Asian breed. It was first evidence on improving the growth and reproductive performance in 196 by 
extending growing legumes to feed the local cattle (Thomas \& Humphreys, 1970). And the first introduced the international cattle breeds into Laos to improve the quality of local cattle breeds was in 1998,
Red Sindhi cattle from Vietnam (Keonouchanh et al., 2014). Pictures about local and improved cattle breeds in Laos are shown on Photo 1 and 2.

Table 2. Comparison of cattle population and commercial cattle farms from 2017 to 2019 (Unit: Head)

\begin{tabular}{|c|c|c|c|c|c|c|}
\hline \multirow{3}{*}{ Provinces } & \multicolumn{2}{|c|}{ Cattle population (head) } & \multicolumn{4}{|c|}{ Commercial cattle farms (unit) } \\
\hline & \multirow{2}{*}{2017} & \multirow{2}{*}{2019} & \multicolumn{2}{|c|}{ Number of farms } & \multicolumn{2}{|c|}{ Number of animals } \\
\hline & & & 2017 & 2019 & 2017 & 2019 \\
\hline Phongsaly & 55,000 & 58,000 & 3 & 3 & 79 & 79 \\
\hline Luangnamtha & 25,000 & 27,000 & N/A & N/A & N/A & N/A \\
\hline Oudomxay & 45,000 & 48,000 & 15 & 44 & 1,147 & 2,607 \\
\hline Bokeo & 62,000 & 66,000 & 16 & 15 & 1,203 & 1,120 \\
\hline Luangprabang & 95,000 & 101,000 & 8 & 10 & 795 & 922 \\
\hline Huaphanh & 84,000 & 89,000 & N/A & N/A & N/A & N/A \\
\hline Xayabury & 141,000 & 150,000 & 13 & 49 & 1,460 & 2,657 \\
\hline Vientiane Capital & 84,000 & 89,000 & 24 & 35 & 2,980 & 3,586 \\
\hline Xiengkhuang & 150,000 & 160,000 & 10 & 10 & 956 & 956 \\
\hline Vientiane & 177,000 & 188,000 & 8 & 8 & 2,754 & 2,754 \\
\hline Borikhamxay & 69,000 & 73,000 & N/A & 34 & N/A & 965 \\
\hline Khammuane & 118,000 & 126,000 & 9 & 19 & 517 & 987 \\
\hline Savannakhet & 456,000 & 485,000 & 9 & 23 & 1,284 & 3,201 \\
\hline Xaysomboun & 39,000 & 41,000 & N/A & N/A & N/A & N/A \\
\hline Saravan & 145,000 & 155,000 & 29 & 20 & 1,474 & 770 \\
\hline Sekong & 29,000 & 31,000 & 5 & 5 & 4,235 & 4,235 \\
\hline Champasack & 181,000 & 192,000 & 23 & 25 & 6,091 & 7,032 \\
\hline Attapeu & 30,000 & 31,000 & 8 & 26 & 1,630 & 13,666 \\
\hline Total & $1,984,000$ & $2,110,000$ & 180 & 326 & 26,605 & 45,537 \\
\hline
\end{tabular}

Source: Department of Livestock and Fishery (2019). N/A: not available

\section{Local cattle breeds}

Although the origin of local cattle breeds in Laos is not exact, they were thought to be introduced from South China during the $13-14^{\text {th }}$ century. This is because most of the current local cattle breeds in Laos are closely related to Chinese Yellow cattle. Local cattle are well adapted to the harsh environment. They can be raised with low inputs of which are favorable to small-scale farmers. They have a relatively good fertility rate with a slow growth rate and the current extensive rearing system that takes around 4-6 years to get the mature body weight. The adult male cattle would reach up to 350 $\mathrm{kg}$ while the female had about $250 \mathrm{~kg}$ (Stur et al., 2002). Similar research (Keonouchanh et al., 2014) showed that the local female cattle always produced one calf per year after 2.5-3 years. The local bulls have a high breeding rate, i.e., covering more than 80 percent of fertilization. However, reproductive breeding records are not yet complied from smallholders. Therefore, data on reproductive efficiency is limited to estimate intercalving interval (ICI), age at first calving (AFC), and calving rate. Based on the available indicators suggested to evaluate the reproductive efficiency were constrained with average cattle had ICIs ranging from 14-20 months, AFC with a minimum of 3 years, calving rate from 51-
70 percent, and expected annual calving after 3 years of age (Olmo, 2020).

\section{Improved breeds and exotic breeds}

In 1998, the first importation of exotic cattle breed occurred with Red Sindhi (4 bulls) and followed by Red Brahman (frozen semen) in 2003, with the support from the Vietnam government (Keonouchanh et al., 2014). Since 2010, the farmers in various parts of Laos have imported hybrid vigours of Thai Grey and Red Brahman, Thai Red Sindhi (Olmo, 2020). Unfortunately, many farmers were not successful due to lack of feed supply, poor quality, insufficient pasture, and lack of experience in these breeds' proper care. This might be one reason why only crossbred (Grey or Red Brahman x local breeds) and (Red Sindhi $\mathrm{x}$ local breed) are found in the country. The general aim of improving local cattle in Laos was to increase beef production to supply the increasing demand of domestic and export consumers to the nearby more significant markets like China and Vietnam, based on the national social-economic development plan from the $6^{\text {th }}$ until now $\left(8^{\text {th }}\right)$. The main purpose of introducing the Brahman cattle breeds into Laos is to improve meat production by crossbreeding with local cattle to fit with Laos's rising environment. This increased the 
performance of hybrid cattle as compared to local cattle breeds (Table 3), especially the birth weight, which was increased from 12 to $21 \mathrm{~kg}$, and growth performance increased from 90 to $150 \mathrm{~kg}$ at 1 year of age (Khouthsavang \& Kounnavong, 2002). Under- supported fund from Asian Development Bank (ADB), 2019 Livestock Research Center (NAFRI) imported 40 Red Brahman bulls from Vietnam to improve local cattle breeds' quality in the north of Laos under a commercial cattle production project.

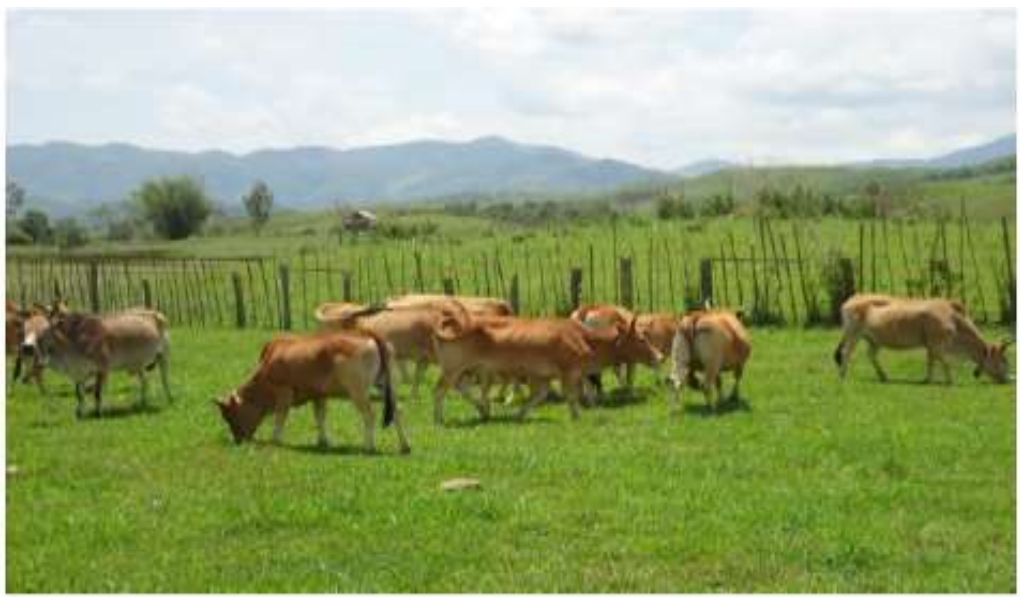

Source: Keonouchanh et al., 2014

Photo 2. Hybrid bulls (Brahman x local breed) raised by a smallholder

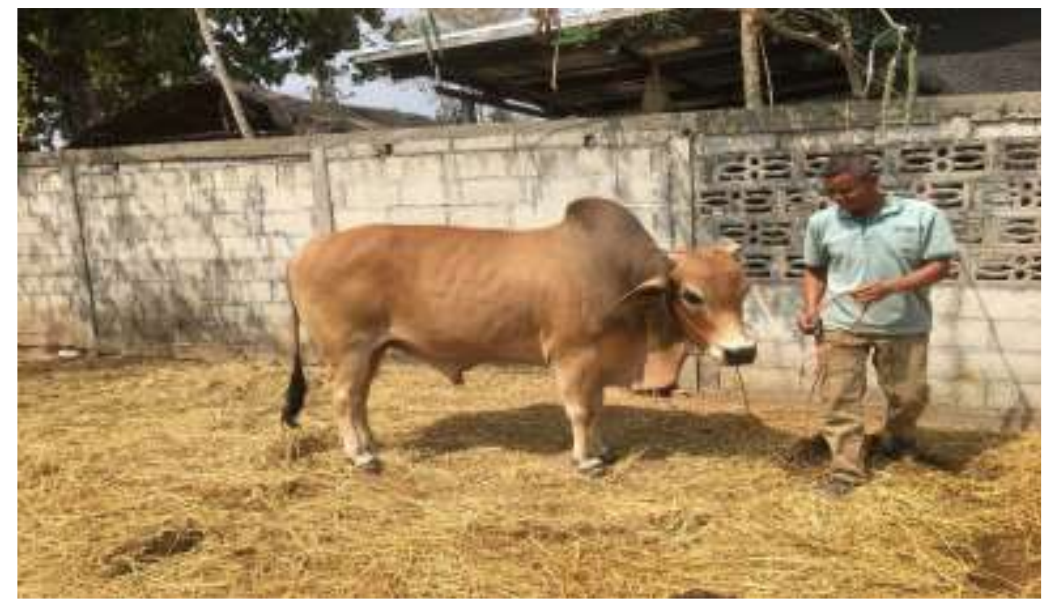

Source: Olmo, 2020

However, Table 3 showed specific parameter of crossbred (Red Brahman x local Lao breed) was higher, nearly twice in comparison to local cattle. However, it is still lower in comparison to the standard internal record of Red Brahman. For example, BreedsBrahman's The Cattle Site, some heifers would be pregnant by the age between 15 to 17 months with bodyweight between 295 to $318 \mathrm{~kg}$. Most Brahman would have their first calving between 2 to 3 years of age (Tran et al., 1988). The mature crossbred between Red Brahman and Lao local breed is also lower in comparison. For instance, the female Red Brahman would weigh between 453 to $635 \mathrm{~kg}$, while males are between 526 to $998 \mathrm{~kg}$ and the birth weight range from $27-29 \mathrm{~kg}$. 
DOI: $10.34101 /$ ACTAAGRAR/1/9047

Table 3. Comparison of productive and reproductive performance of local and crossbred of cattle bred in Laos

\begin{tabular}{lcc}
\hline Parameters & Local cattle & Hybrid (Red Brahman X Local breed) \\
\hline Age at first calving (year) & $2.5-3$ & 3 \\
Weight at first calving $(\mathrm{kg})$ & $180 \pm 17.26$ & $306 \pm 15.81$ \\
Birth weight $(\mathrm{kg})$ & 12 & $21 \pm 3.2$ \\
Weight at 1 year of age $(\mathrm{kg})$ & $90 \pm 3.16$ & $150 \pm 6.5$ \\
Weight at 4-9 years of age $(\mathrm{kg})$ & $250 \pm 39.37$ & $450 \pm 13.85$ \\
ADG $(\mathrm{g})$ & N/A & 431 \\
\hline
\end{tabular}

Source: Khouthsavang \& Khounnavongsa. (2002). ADG: Average Daily gain

\section{PIG BREEDS IN LAOS}

Pig production in Laos had a steady increase from 1976 to 1995 (Figure 2). However, due to the national policy changed in agricultural production, the industry experienced a drop in population from 1995 to 2000. With the continuous demand for pork and government projects for mass production, it spiked from the year 2000 and has been steadily increasing until now. The indigenous pig breeds are still essential domestic animals in Laos, i.e., covering more than 91 percent of the total pig population (3.1 million) in Laos in 2014. Almost $85 \%$ of them were raised by smallholders particularly, in remote or mountainous areas (Keonouchanh, 2018).

The number of commercial pig farms slightly increased from 572 in 217 to 578 farms in 2019. The number of animals also went up to 359,612 heads (increased 26\%) compared to 2017 (Table 4). More than 81 percent $(291,869$ heads) are located in the central part, $14 \%(49,271$ heads $)$ in the north, and $5 \%$ $(18,472$ heads) in the south (DLF, 2019).

Figure 2. The trends of pig population in Laos from 1975-2019

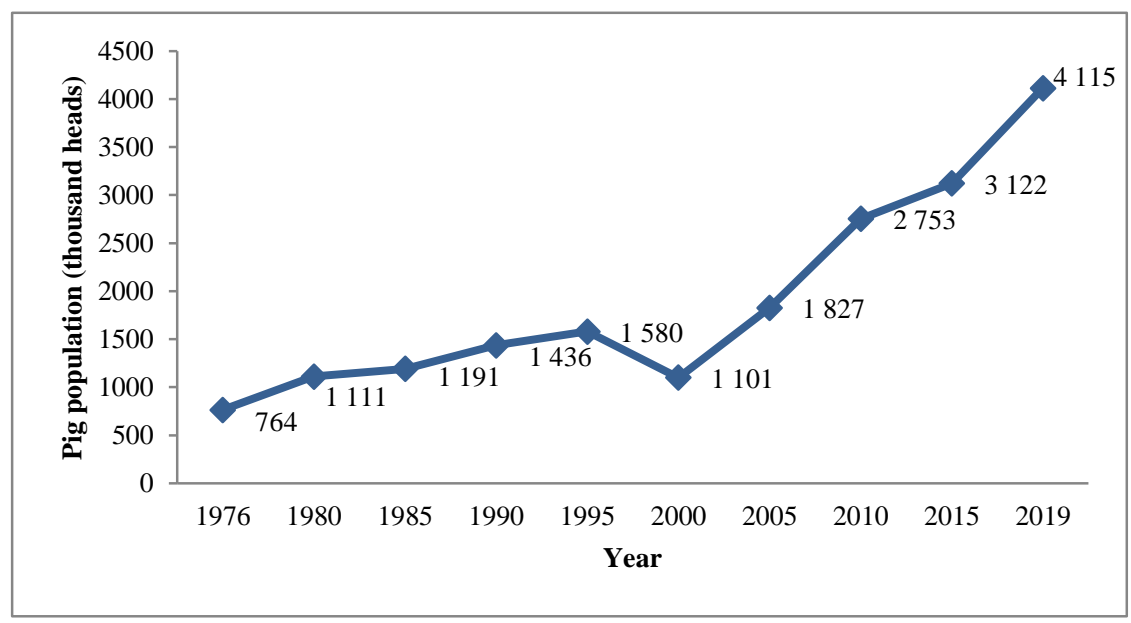

Source: Lao Statistics Bureau (2015); MAF (2020)

However, Laos had a long history (more than 40 years) of developing pig breeds. However, the pig breeds seem not improved, including indigenous, exotic (Large White, Landrace, and Duroc), and improved breeds (Local breed $x$ Duroc). In this circumstance, I will briefly discuss some strategies concerning pig breeds development in Laos for both local pig breeds and exotic breeds, including the improved breed.

\section{Indigenous pig breeds}

The origin of four types of Laos local pig breeds is unclear. However, there was a hypothesis (without any evidence) that Moo Deng (local name, Photo 3) resulted from crossbreeding Lao native sow and Berkshire boar from 1893 to 1954 during the French occupation of Laos. Moo Hmong (local name, Figure 4) was also assumed to be first imported into Laos during the first half of the $19^{\text {th }}$ century by the Hmong tribe. This tribe migrated from Southern China to live in Nong Haed district in Xiengkhouang province, Laos. Unfortunately, for Moo Chid and Moo Lath breeds (Figure 4), no information regarding their origin is obtained. The statistic record about pig breeds is still based on general information (population) gathered by the district agriculture and forestry office (DAFO). Based on the existing data, it is still premature to estimate reproductive performance and other parameter performance of pigs in Laos. 
Table 4. Comparison of pig population and commercial pig farms from 2017 to 2019 (Unit: Head)

\begin{tabular}{|c|c|c|c|c|c|c|}
\hline \multirow{3}{*}{ Provinces } & \multicolumn{2}{|c|}{ Pig population } & \multicolumn{4}{|c|}{ Commercial farms } \\
\hline & \multirow{2}{*}{2017} & \multirow{2}{*}{2019} & \multicolumn{2}{|c|}{ Number of farms } & \multicolumn{2}{|c|}{ Number of animals } \\
\hline & & & 2017 & 2019 & 2017 & 2019 \\
\hline Phongsaly & 275,000 & 290,000 & 1 & 1 & 300 & 300 \\
\hline Luangnamtha & 132,000 & 138,000 & 5 & 5 & 2,450 & 2,450 \\
\hline Oudomxay & 204,000 & 216,000 & 28 & 32 & 2,031 & 3,1444 \\
\hline Bokeo & 89,000 & 93,000 & 9 & 9 & 1,097 & 1,097 \\
\hline Luangprabang & 275,000 & 291,000 & 19 & 37 & 9,521 & 27,696 \\
\hline Huaphanh & 192,000 & 203,000 & 2 & 2 & 261 & 201 \\
\hline Xayabury & 178,000 & 186,000 & 52 & 29 & 9,986 & 14,323 \\
\hline Vientiane Capital & 173,000 & 215,000 & 156 & 188 & 153,710 & 212,612 \\
\hline Xiengkhuang & 127,000 & 134,000 & N/A & N/A & N/A & N/A \\
\hline Vientiane & 140,000 & 147,000 & 43 & 43 & 22,200 & 22,200 \\
\hline Borikhamxay & 94,000 & 98,000 & 11 & 21 & 5,267 & 14,121 \\
\hline Khammuane & 122,000 & 128,000 & 98 & 98 & 26,314 & 26,314 \\
\hline Savannakhet & 380,000 & 403,000 & 63 & 33 & 10,052 & 16,622 \\
\hline Xaysomboun & 31,000 & 32,000 & N/A & N/A & N/A & N/A \\
\hline Saravan & 945,000 & $1,003,000$ & 39 & 31 & 2,286 & 3,124 \\
\hline Sekong & 172,000 & 181,000 & 5 & 5 & 12,275 & 12,275 \\
\hline Champasack & 285,000 & 302,000 & 38 & 42 & 25,444 & 2,723 \\
\hline Attapeu & 54,000 & 55,000 & 3 & 3 & 269 & 350 \\
\hline Total & $3,869,000$ & $4,115,000$ & 572 & 578 & 284,454 & 359,612 \\
\hline
\end{tabular}

Source: Department of Livestock and Fishery (2019). N/A: not available
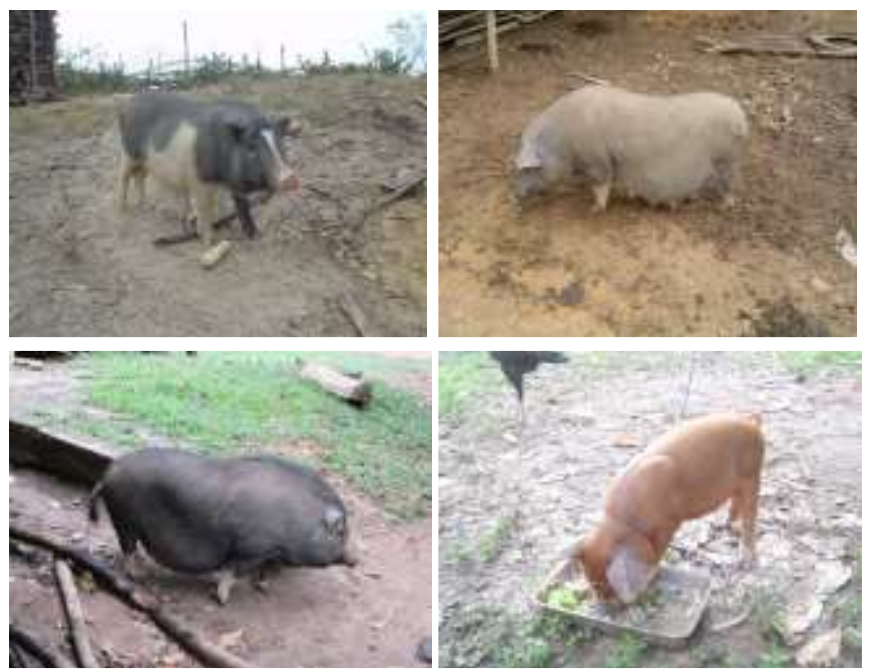

Reliable information on Laos native pig breeds was covered by Keonouchanh et al. (2011): Moo Chid exhibits its first oestrus at 6 months with bodyweight between 21 to $31 \mathrm{~kg}$. The average age at the first farrowing was 360 days, litter per year was 1.5 , and litter size was between 7-8 piglets. The farmers typically wean the piglets around 3 months of age, and the average weaning weight was $7.8 \mathrm{~kg}$. The weight of mature sows was between 42 to $48 \mathrm{~kg}$, while the boar was around 18-30 kg. Moo Hmong can reach its first oestrus between 5 to 6 months of age with a bodyweight of about $30-40 \mathrm{~kg}$. The first farrowing age was around
10-11 months and approximately $1.5-1.8$ litter per year, with the number of litter size around 7-10 piglets. The normal weaning period is around 2-3 months, and the average weaning weight is about $8 \mathrm{~kg}$. The mature size of sow and boar were not different body weight, between 60 to $85 \mathrm{~kg}$. Moo Lath can reach its first oestrus at 189 to 586 days old (based on the rearing system and feeding regime) with an average body weight of $39 \mathrm{~kg}$. The youngest age of first farrowing was around 360 days and approximately 1.5-1.8 litter per year with about 7-8 piglets per litter. Farmers 
always wean their piglets between 2-3 months of age with an average weaning weight of $9.5 \mathrm{~kg}$.

Interestingly, boars are lighter (30 to $50 \mathrm{~kg}$ mature weight) than sows (47 to $61 \mathrm{~kg}$ mature weight), unlike other purebreds. Moo Deng can reach its first farrowing at the age of 330-360 days, and around 1.5-1.8 litter per year with about $7-10$ piglets per litter. The weaning period took around 2-3 months, with the average weight of piglet around $8.5 \mathrm{~kg}$. Mature sow and boar have similar body sizes (65 to $90 \mathrm{~kg}$ ).

\section{Exotic and improved breeds}

Under supporting fund from FAO, the National Agriculture and Forestry Research Institute of Laos (NAFRI) imported the first 120 sows (Large White, Landrace, Duroc) from Thailand in 1980. FAO also continued to support funds to establish 1,200 sows for the national pig research center to produce two lines of crossbred pigs (Large White $\mathrm{x}$ Duroc) to increase the country's pig production (Keonouchanh \& Dengkhounxay, 2017). Unfortunately, Laos has no transparent recording system on specific parameters of pigs' growth and reproductive performance. There is no available scientific research related to the exotic pig breeds in Laos. Most of the existing data is based on population (Table 4). Therefore, it is hard to estimate all reproductive performance parameters of exotic pig breeds currently raising in Laos. Due to the pig production sector's industrialization, there is a need to further search regarding exotic pig breeds in Laos for both productive and reproductive performance.

Table 5. Comparison of reproductive performance of pig breeds in Laos

\begin{tabular}{lcc}
\hline Parameters & Moo Lath & Improved breed (Back pig) \\
\hline First oestrus of age, day & 189 & 203 \\
First mating of age, day & 110 & 222 \\
First farrowing of age, day & 360 & 380 \\
Litter per year, time & 1.6 & 2.3 \\
Piglet per litter, head & 7.5 & 9 \\
Birth weight, kg & 0.7 & 1.17 \\
Weaning weight, $\mathrm{kg}$ & $4(30$ days $)$ & $6.7 \mathrm{~kg}(30$ day $)$ \\
\hline
\end{tabular}

Source: Keonouchanh, 2018

From 2012 to 2018, the livestock research center (NAFRI) had developed the black pig breed resulted from crossbreeding native pig (NP) $\mathrm{x}$ Landrace (LR) $\mathrm{x}$ Duroc (DR). The resultant breed has improved litter size, growth rate, and meat quality for smallholder farmers who use local feed resources. The result showed ADG was increased from 100-120 $\mathrm{g} \mathrm{day}^{-1}$ to more than $500 \mathrm{~g} \mathrm{day}^{-1}$, and the litter size was higher than 8 piglets per litter (Keonouchnah and Dengkhamxay, 2017). From 2016 to 2018, the livestock research center had the supporting fund by the KOPIA project (Korean Program on International Agriculture) to further improve the native pig breed by crossbreeding (NP $\mathrm{x}$ DR) to promote household production. The crossbred had better reproductive performance (Table 5) based on litter per year, litter size, birth weight, and weaning weight compared to NP "Moo Lath" (Keonouchanh, 2018) and has relative values to exotic breeds.

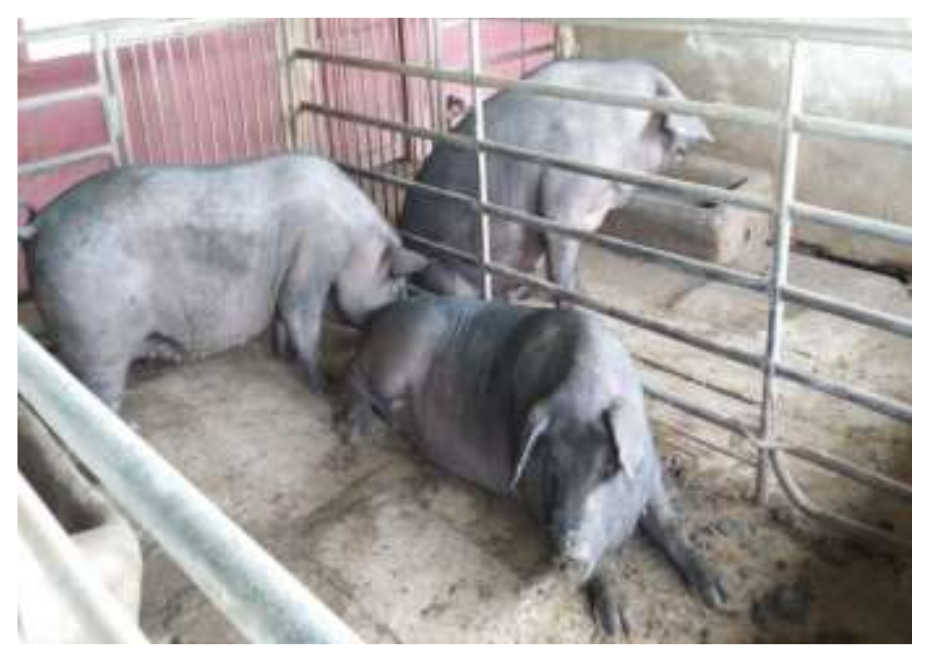




\section{GOAT BREEDS IN LAOS}

Goat production in Laos has been growing faster during the last 10 years. The number of goats in Laos with a period of 5 years between 2005 and 2010 increased more $92 \%$ and increased more $34 \%$ compared in 2019 compared to 2015 (Figure 6). Based on the national agriculture survey in $2019,41 \%$ of Laos's goat population was in the north, 42 percent in the middle, and $17 \%$ in the south. It was slightly down in the north from $47 \%$, and more twice increased in the south with only 7 percent in 2013 . More than $85 \%$ of the goat production system was based on free-range around the year (Keonouchanh et al., 2014). There were 93 commercial goat farms in 2019 increased of $29 \%$ compared to 2017 ( 72 farms), including 16 in the north, 59 in the middle, and 18 farms in the south (Table 6; MAF, 2020). Laos' goat production's noticeable problem is the low breeding plan and management, where a poor selection of breeding buck and inbreeding always happen (Helena, 2010).

Figure 3. The trends of goat population in Laos from 1975-2019

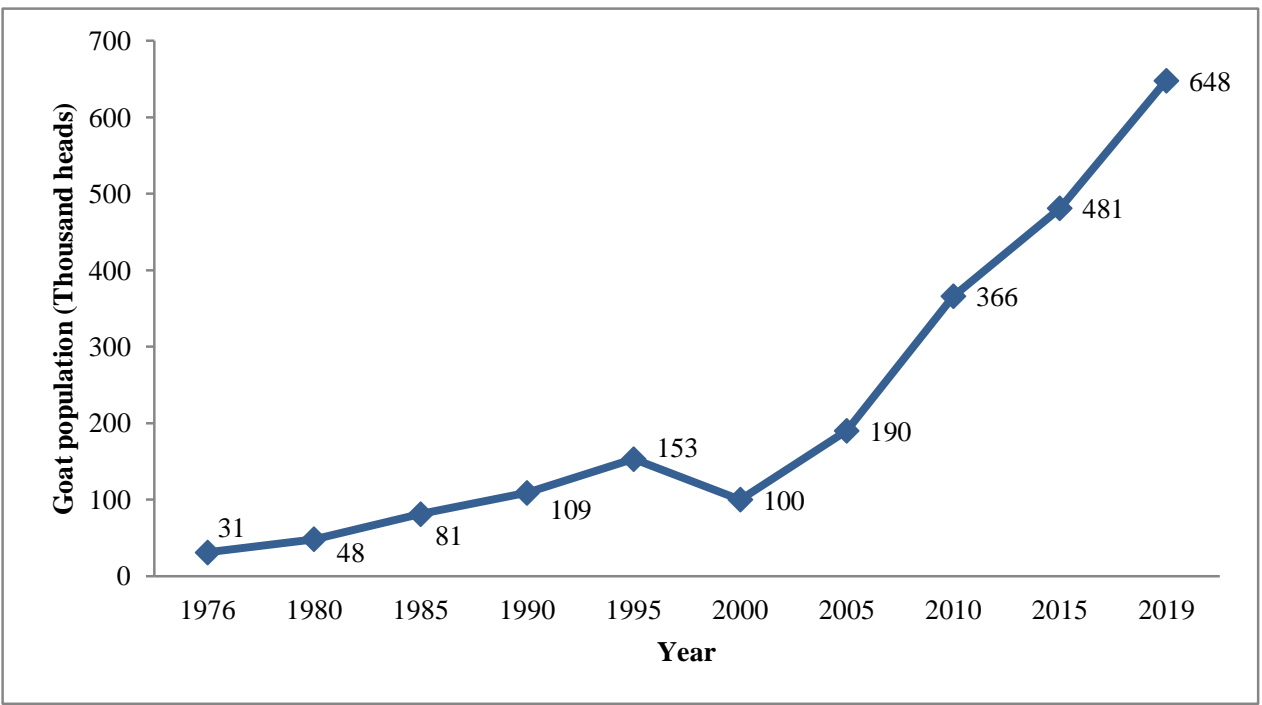

Source: Lao Statistics Bureau (2015); MAF (2020)

The indigenous goat breeds in Laos are not different from other countries in the region. The Katjang goats were found in every part of Laos and commonly found in South East Asia. The goats would get the mature weight of around $40 \mathrm{~kg}$, can experience their first kidding at the age of 12 to 18 months (based on a freerange system of farmers), usually a single kid. Most of the goat breeds in Laos are reared for meat production purposes (Stur et al., 2002). The Does would give birth to twins or sometimes triple kids, an average of 2.1 kids per parturition and 1.4 parturitions per year from the second and third parturition. The birth weight was around $1.1-1.5 \mathrm{~kg}$, weaning weight $9.7 \mathrm{~kg}$, and the bodyweight at the first oestrus was around 14-15 kg. The buck's mature weight is between $35-38 \mathrm{~kg}$, while the Does is between 31-32 kg (Phengsavanh et al., 2004). Most goats raised in Laos are commonly native mixed breed, grouped in the Southeast Asian Mountainous goat breeds. There has been no described genetic evidence up to now (Wilson, 2007). Xaypha (2005) also had a short description of local goat breeds in Laos. Most of them are well fertile and well adapted to the poor rearing condition environment. The local goat in the lowland would reach the mature weight of around $40 \mathrm{~kg}$, but the average live weight was approximately $26.8 \mathrm{~kg}$ for the female and $31.8 \mathrm{~kg}$ for the male in the free-range rearing system, and around $27.3 \mathrm{~kg}$ and $32.3 \mathrm{~kg}$ respectively, for the semi-rearing system.

However, some parts of Laos can find improved goat breed as Boer, which was assumed to be imported from Thailand. There is no evidence mentioned about the history of when the foreign breed (Boer) was the first improved into Laos. Therefore, all data or information about Boer goat in Laos is needed, and more research must be done. Between the years 2001 to 2003, 20 Bach Thao goats were introduced from Vietnam to Livestock Research Center in Laos to improve local goat breeds (Xaypha, 2005). Unfortunately, until today there is still no scientific research paper that covers this breed and its development in the country. Besides, this type of breed is hard to find in Laos at present. It might have already mixed or crossed with other local goat breeds, hard to distinguish by ocular observation. 
Table 6. Comparison of goat population and commercial goat farms from 2017 to 2019 (Unit: Head)

\begin{tabular}{|c|c|c|c|c|c|c|}
\hline \multirow{3}{*}{ Provinces } & \multicolumn{2}{|c|}{ Goat population } & \multicolumn{4}{|c|}{ Commercial farms } \\
\hline & \multirow{2}{*}{2017} & \multirow{2}{*}{2019} & \multicolumn{2}{|c|}{ Number of farms } & \multicolumn{2}{|c|}{ Number of animals } \\
\hline & & & 2017 & 2019 & 2017 & 2019 \\
\hline Phongsaly & 16,000 & 18,000 & 3 & 3 & 183 & 163 \\
\hline Luangnamtha & 17,000 & 19,000 & N/A & N/A & N/A & N/A \\
\hline Oudomxay & 31,000 & 33,000 & 8 & 8 & 335 & 335 \\
\hline Bokeo & 31,000 & 34,000 & N/A & N/A & N/A & N/A \\
\hline Luangprabang & 93,000 & 102,000 & 5 & 3 & 295 & 170 \\
\hline Huaphanh & 38,000 & 42,000 & 2 & 2 & 120 & 120 \\
\hline Xayabury & 14,000 & 16,000 & N/A & N/A & N/A & N/A \\
\hline Vientiane Capital & 28,000 & 31,000 & 3 & 10 & 585 & 1,111 \\
\hline Xiengkhuang & 27,000 & 30,000 & 4 & 4 & 537 & 537 \\
\hline Vientiane & 28,000 & 30,000 & N/A & N/A & N/A & N/A \\
\hline Borikhamxay & 33,000 & 36,000 & 27 & 38 & 1,241 & 1,499 \\
\hline Khammuane & 34,000 & 37,000 & N/A & N/A & N/A & N/A \\
\hline Savannakhet & 93,000 & 103,000 & 2 & 7 & 273 & 757 \\
\hline Xaysomboun & 4,000 & 5,000 & N/A & N/A & N/A & N/A \\
\hline Saravan & 47,000 & 52,000 & 5 & 5 & 200 & 200 \\
\hline Sekong & 30,000 & 33,000 & 6 & 6 & 1,250 & 1,250 \\
\hline Champasack & 18,000 & 20,000 & 2 & 2 & 350 & 350 \\
\hline Attapeu & 6,000 & 7,000 & 5 & 5 & 192 & 192 \\
\hline Total & 588,000 & 648,000 & 72 & 93 & 5,561 & 6,684 \\
\hline
\end{tabular}

Source: MAF (2020). N/A: not available

GOVERNMENT POLICY TO SUPPORT AND DEVELOP LIVESTOCK PRODUCTION IN LAOS

In the agricultural development strategy plan to 2025 and the vision for the year 2030 (MAF, 2015), the Lao government indicated a clear policy to support and develop livestock production sectors. Cattle is one of the livestock species with high potential support to grow as an export product. Between 2020-2025, Lao expected to export around 15,000 tons of beef, including beef from local breeds (10,500 tons) and crossbred (4,500 tons) by supporting native cattle production to reach 87,000 heads, crossbred about 28,000 head. To achieve the mentioned goal, the government identify some measurements to implement, which include: (1) promote farmers to build up more native cattle farms and operate as a good farming practice in cattle production. They shall have a breed improvement to increase the bodyweight up to 300 $\mathrm{kg} / \mathrm{head}$. (2) Promote crossbreeding to cattle farmers by using AI technology to increase cattle's bodyweight up to $400 \mathrm{~kg} / \mathrm{head}$ or increase their meat products up to 160 $\mathrm{kg} / \mathrm{head}$. (3) Promote farmers to expand their grassland to grow high yield grasses to feed the animals.

For commercial pig production in Laos, it is still a small-scale operation that cannot compete internationally. Therefore, the exhibition aims to be a sufficient domestic supply, and the government set up the following supporting measures: (1) Promote crossbred pig production by supporting both backyards and commercial sectors to produce more breeding stocks (F1 and F2). They are to be located in each part of the country and set up production and sufficient supply of piglets to reduce the importation from neighboring countries. (2) Promote three-way crossed (three-bloodline) pigs for pork production, particularly in the areas with high potential. The goal is to increase the country's self-sufficiency of pork supply from the current 15 to $50 \%$ supplied from locally produced pork out of the country's total pork demand.

Goats are one of the potential sources of meat supply. By 2025 , the goal is to supply $4,000-5,000$ tons of goat meat per year or increase at least 250,000 heads produced by commercial goat farms. Therefore, there is a need to encourage more investment in goat farming operations and expand goat production in areas that have potential like Phongsaly, Oudomxay, Houaphanh, Xiengkhouang, Vientiane, Borikhamxay, SaravanF Xekong, and Attapeu provinces to be as a source of goats for breeding. The most critical and urgent issues to be addressed are improving and developing local goat breeds to have a larger body size and resistance to the harsh environment and encourage smallholder farmers to raise more goats.

\section{FUTURE STUDIES AND RESEARCHES NEED FOR IMPROVING THE CURRENT LIVESTOCK PRODUCTION IN LAOS}

Overall, there is still in limitation on studying and doing research about animal breeding in Laos, particularly the research related to animal breeding improvement. Therefore, in the agriculture development strategy for 2025 and the vision for 2030 (MAF, 2015), the Lao government indicated some measurements to support commercial livestock production research such as (1) Promote research on conservation of local animals and fish genetic resources 
and improving them to supply meat for commercial purposes. (2) Research to improve varieties, products and expand animals for breeding that have commercial potentials such as indigenous crossbred cattle, pigs, and goats. (3) Promote the research on improving the production systems and supplying animal breeds for commercial purposes. (4) Promote the research on adaptation the advanced technologies to improve animals and fishery production systems for modern farms and finished products and semi-finished products. (5) Promote the research on recent techniques and technologies to improve animals and fish raising system, including raising indigenous animals (native pig, chicken, goat, cattle) of smallholder production. (6) Promote the research on the policy for accessing animal breeds and fish and animal raising techniques to reduce production cost. (7) Promote the research on livestock and fisheries information to define policies and mechanisms on animal and fishery, including marketing for small farmers' commercial production system.

\section{CONCLUSIONS}

Data on animal breeding and livestock production in Laos are still insufficient. Based on the current condition, Laos has limited data and scientific information regarding animal breeding compared to other countries. The quality and productive performance of indigenous breeds may be enhanced through animal breeding. Thus it is vital for the government's aim of self-reliance. Moreover, there is still no clear or relevant data to compare local, exotic, and improved animal breeds in Laos. Laos lacks enough animal breeding related reports and scientific publications. Most responsible organizations do not have the proper way to communicate or present their results to the public. Thus, most of the research results are always kept, which minimizes information flow to the public. Anyway, our review suggests some specific activities should take into action. For cattle: improving nutrition, health, and adaptation of breeding management should be considered to enhance reproductive efficiency. The key issues to view on improving the quality of local breeds should be; proper bull selection, controlling breeding season (support calving during the wet season, which has more available natural pastures) and adequate weaning, and crossbreeding to increase the body weight and growth rate of local breeds. Promote local pig production to meet domestic consumers' requirements and larger neighboring markets such as Vietnam and China. It is necessary to promote the unique characteristic products and convert the output from simple traditional to semiintensive farming systems to increase the quantity and improve products' quality. There should be a precise classification between the conservative and the production line of native pig breeders. One option to promote the market-oriented should be crossbreeding between local pigs and exotic breeds. Other hands, housing, and feeding technologies are also two crucial points to be considered to improve the farming system. The inadequate nutritional supplies, including quality and quantity, are still a concrete challenge that blocks goat development progress in Laos. These issues should be resolved by improving techniques of using the local feed sources. The second priority to be addressed is improving kidding procedures, which have been neglected in many areas. More than $50 \%$ of kids died before weaning, and most kids were stunts (6-8 months to get $15 \mathrm{~kg}$ of body weight), which have a significant impact on productivity. Buck selection is another crucial point to be considered to develop local breeds' genetics and increase the bodyweight of the slaughter goats. In conclusion, more researches regarding essential aspects of animal productive and reproductive performance, purebred and crossbred, should be more conducted to make sure for the right direction of improving livestock breeding and production in Laos.

\section{ACKNOWLEDGEMENTS}

This work was supported by Hungarian Stipendium Hungaricum Programme.

\section{REFERENCES}

Department of Livestock and Fishery (2019): Livestock statistic from 2014-2019. Ministry of agriculture and forestry. Vientiane Capital, Lao PDR.

Helena, A. (2010): Goat production in Laos and the potential of using Erythrina Variegata as a feedstuff. Department of Animal nutrition and Management. Bsc. Thesis. Swedish University of Agricultural Sciences. https://stud.epsilon.slu.se/935/3/allard_helena_100322.pdf

Keonouchanh, S.-Egerszegi, I.-Ratky, J.-Bouahom, B.-Manabe, N.Brussow, K.P. (2011): Native pig (Moo Lath) in Laos. Archiv Tierzucht. 54,6: 600-606.

Keonouchanh, S.-Phengsavanh, P.-Somchanh, K. (2014): Complied for study and research on Lao local livestock breeds. Lao livestock development and research center, national agriculture and forestry research institute (NAFRI).
Keonouchanh, S.-Dengkhounxay, T. (2017): Pig production and pork quality improvement in Lao PDR. Online https://www.angrin.tlri.gov.tw/meeting/2017TwVn/2017TwVn _p37-42.pdf

Keonouchanh, S. (2018): KOPIA Project Final Report year 20162018 on improving livelihood of farmers by chicken and pig raising in Mork district, Xiengkhuang Province. Livestock research center. National agriculture and forestry research institute (NAFRI) of Laos.

Khothsavang, B.-Kounnavongsa, B. (2002): Experiment on improving the quality of local cattle by crossbreeding with Red Brahman bull. Journal of national agriculture and forestry institute. 4:21-28. 
Lao Statistics Bureau (2015): Statistic for 40 Years 1975-2015 Ministry of Planning and Investment, Vientiane capital. Lao PDR.

MAF (2010): Strategy for agricultural development 2011 to 2020 Agriculture development strategy 2020. Ministry of Agriculture and Forestry of Laos. Online https://www.gafspfund.org/sites/default/files/inlinefiles/5.\%20LaoPDR_strategy.pdf

MAF (2015): Agriculture development strategy to 2025 and vision to the year 2030. Ministry of Agriculture and Forestry of Laos. http://www.maf.gov.la/wpcontent/uploads/2016/01/MDS-2025-and-Vision-to-2030Eng.pdf

MAF (2020): Agricultural statistic, Year Book 2019. Ministry of Agriculture and forestry, Vientiane capital, Lao PDR. https://alisea.org/aliseaonlinelibrary/laos-agricultural-statistics-year-book2019/

Ministry of planning and investment (2016): $8^{\text {th }}$ Five-year national socio-economic development plan 2016-2020. Pp 4-13. Online https://laopdr.un.org/13284-8th-national-socio-economicdevelopment-plan-2016-2020

Napasirth, P.-Napasirth, V. (2018): Current situation and future prospects for beef production in Lao People's Democratic Republic - A review. Asian-Australian journal of animal sciences. 31,7:961-967. https://doi.org/10.5713/ajas.18.0206

Olmo, L. (2020): Investigating smallholder cattle and buffalo reproductive health and management in Lao PDR to enhance reproductive efficiency and improve livelihoods. A thesis submitted in fulfilment of the requirements for the degree of Doctor of Philosophy. Sydney School of Veterinary, The university of Sydney. pp. 36-48. Online https://ses.library.usyd.edu.au/handle/2123/21744
Phengsavanh, P.-Ledin, E.-Bouahom, B. (2004): Effect of supplement Stylo 184 and Gamba grass on the feed of Lao indigenous goat. Journal of NAFRI. 8:14-31.

Phouyyavong, K.-Tomita, Sh.-Yokoyama, S. (2019): Impact of forage introduction on cattle grazing practices and croplivestock systems: a case study in an upland village in northern Laos. The rangeland journal. 41:323-334. Available at https://doi.org/10.1071/RJ18102

Thomas, R.-Humphreys, L.R. (1970): Pasture improvement at Na Pheng, central Laos. Tropical grasses. 4,3: 229-236.

Tran, T.Q.-Warnick, A.C.-Hammond, A.E.-Koger, M. (1988): Reproduction in Brahman cows calving for the first time at two or three years of age. Theriogenology. 29,3:751-756. DOI: 10.1016/s0093-691x(88)80019-0

Stur, W.-Gray, D.-Bastin, G. (2002): Review of the livestock sector in the Lao People's Democratic Republic. International livestock research institute. Online https://cgspace.cgiar.org/bitstream/handle/10568/21136/adb_liv estock_review.pdf?sequence $=2$

Wilson, R.T. (2007): Status and prospects for livestock production in the Lao People's Democratic Republic. Trop Anim Health Prod. 39:443-452.

Xaypha, S. (2005): Goat production in smallholder farming systems in lowland in Lao PDR and an evaluation of different forages for growing goats. NAFRI of Laos. https://citeseerx.ist.psu.edu/viewdoc/download?doi=10.1.1.539. $3324 \&$ rep=rep $1 \&$ type $=$ pdf 
